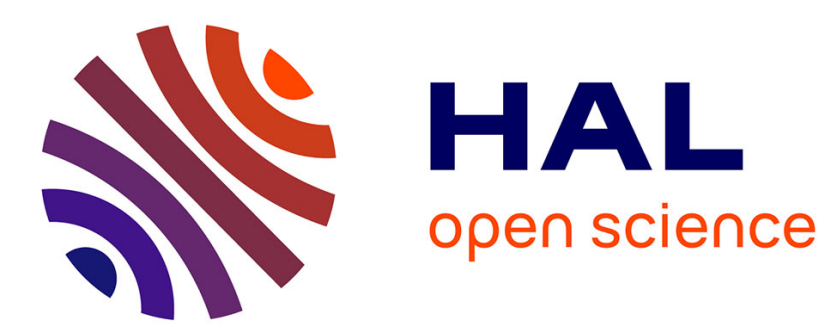

\title{
Yet another short proof of Bourgain's distortion estimate for embedding of trees into uniformly convex Banach spaces
}

Benoît Kloeckner

\section{- To cite this version:}

Benoit Kloeckner. Yet another short proof of Bourgain's distortion estimate for embedding of trees into uniformly convex Banach spaces. Israel Journal of Mathematics, 2014, 200 (1), pp.419-422. 10.1007/s11856-014-0024-4 . hal-00785961

\section{HAL Id: hal-00785961 \\ https://hal.science/hal-00785961}

Submitted on 7 Feb 2013

HAL is a multi-disciplinary open access archive for the deposit and dissemination of scientific research documents, whether they are published or not. The documents may come from teaching and research institutions in France or abroad, or from public or private research centers.
L'archive ouverte pluridisciplinaire HAL, est destinée au dépôt et à la diffusion de documents scientifiques de niveau recherche, publiés ou non, émanant des établissements d'enseignement et de recherche français ou étrangers, des laboratoires publics ou privés. 


\title{
Yet another short proof of Bourgain's distorsion estimate
}

\author{
Benoît R. Kloeckner ${ }^{1, *}$ \\ ${ }^{1}$ Institut Fourier, Université de Grenoble I
}

\begin{abstract}
We use a self-improvement argument to give a very short and elementary proof of the result of Bourgain saying that regular trees do not admit bi-Lipschitz embeddings into uniformly convex Banach spaces.
\end{abstract}

Let $T_{n}$ be the binary rooted tree of depth $n$ and let $c_{B}(A)$ denote the distorsion of the metric space $A$ in $B$, that is to say the infimum of all numbers $D$ such that there is a number $s$ and a map $\varphi: A \rightarrow B$ such that

$$
s d(x, y) \leqslant d(\varphi(x), \varphi(y)) \leqslant s D d(x, y)
$$

for all $x, y \in A$.

The modulus of (uniform) convexity $\delta_{X}(\varepsilon)$ of a Banach space $X$ with norm $|\cdot|$ is defined as

$$
\inf \left\{1-\left|\frac{x+y}{2}\right||| x|=| y \mid=1 \text { and }|x-y| \geqslant \varepsilon\right\}
$$

for $\varepsilon \in(0,2]$. The space $X$ is said to be uniformly convex of type $p \geqslant 2$ if $\delta_{X}(\varepsilon) \geqslant c \varepsilon^{p}$ for some $c>0$. Note that in particular, for $p \in(1, \infty)$ the $L^{p}$ spaces are uniformly convex of type $\max (2, p)$.

Our main goal is to prove the following as simply as possible.

Theorem 1 (Bourgain). If $X$ is uniformly convex of type $p$ then

$$
c_{X}\left(T_{n}\right) \gtrsim(\ln n)^{\frac{1}{p}} .
$$

Several proofs of this result have been given over the years, see notably $[1,3,4]$. As we discovered after writing a first draft of this paper, the method we use is very close to Johnson and Schechtman's proof of the distorsion estimate for diamond graphs [2]. However, it seems not to have been noticed before that this method gives such an effective proof of Bourgain's estimate.

Proof. The first step is similar to previous proofs, notably the one by Matoušek's [3]. Let $Y$ be the four-vertices tree with one root $a_{0}$ which has one child $a_{1}$ and two grandchildren $a_{2}, a_{2}^{\prime}$.

Lemma 2. There is a constant $K=K(X)$ such that if $\varphi: Y \rightarrow X$ is D-Lipschitz and distance non-decreasing, then either

$$
\left|\varphi\left(a_{0}\right)-\varphi\left(a_{2}\right)\right| \leqslant 2\left(D-\frac{K}{D^{p-1}}\right)
$$

or

$$
\left|\varphi\left(a_{0}\right)-\varphi\left(a_{2}^{\prime}\right)\right| \leqslant 2\left(D-\frac{K}{D^{p-1}}\right)
$$

\footnotetext{
* benoit.kloeckner@ujf-grenoble.fr
}

We provide the proof below for the sake of completeness.

Let now $\varphi: T_{n} \rightarrow X$ a $D$-Lipschitz, distance nondecreasing map. By the lemma, the root $a_{0}$ has at least two grand-children $a_{2}^{i}(i=1,2)$ such that

$$
2 \leqslant\left|\varphi\left(a_{0}\right)-\varphi\left(a_{2}^{i}\right)\right| \leqslant 2 f(D)
$$

where $f(D)=D-K / D^{p-1}$. Applying the lemma again, each of $a_{2}^{i}$ also has two grand-children satisfying similar inequalities, and we can apply he same reasoning every other generation. Restricting $\varphi$ to these vertices, we get an embedding of $T_{\left\lfloor\frac{n}{2}\right\rfloor}$ whose distorsion is at most $f(D)$.

We can iterate these restrictions $\left\lfloor\log _{2}(n)\right\rfloor$ times to get an embedding of $T_{1}$ whose distorsion is $f^{\left\lfloor\log _{2}(n)\right\rfloor}(D)$. This must be at least 1 and $f^{D^{p} / K}(D)<1$, so that

$$
\log _{2}(n) \lesssim D^{p}
$$

which is Theorem 1.

Remark 3. Working out the constants gives the more precise result that

$$
c_{X}\left(T_{n}\right) \geqslant\left(\frac{p c}{2}\right)^{\frac{1}{p}}\left(\log _{2} n\right)^{\frac{1}{p}}+\text { l.o.t. }
$$

where $c$ can be replaced by $\lim \inf \delta_{X}(\varepsilon) \varepsilon^{-p}$. In particular

$$
c_{\ell^{2}}\left(T_{n}\right) \geqslant \frac{1}{2 \sqrt{2}}\left(\log _{2} n\right)^{\frac{1}{2}}+\text { l.o.t. }
$$

Proof of Lemma 2. Assume $\varphi\left(a_{0}\right)=0$ and let $x_{1}=$ $\varphi\left(a_{1}\right), x_{2}=\varphi\left(a_{2}\right)$ and $x_{2}^{\prime}=\varphi\left(a_{2}^{\prime}\right)$.

Suppose that $\left|x_{2}\right| \geqslant 2(D-\eta)$ for some $\eta$ to be chosen afterward; then by the triangle inequality, $\left|x_{1}\right|$ and $\mid x_{2}-$ $x_{1} \mid$ are at least $D-2 \eta$.

Define $v=\frac{\left|x_{1}\right|}{\left|x_{2}-x_{1}\right|}\left(x_{2}-x_{1}\right) ;$ then

$$
\left|x_{1}+v-x_{2}\right|=|| x_{1}|-| x_{2}-x_{1}|| \leqslant 2 \eta
$$

and

$$
\left|x_{1}+v\right| \geqslant\left|x_{2}\right|-\left|x_{1}+v-x_{2}\right| \geqslant 2 D-4 \eta .
$$

The vectors $x_{1} /\left|x_{1}\right|$ and $v /\left|x_{1}\right|$ have unit norm and their average has norm at least $1-2 \eta / D$; letting $\varepsilon=$ $(2 \eta / c D)^{\frac{1}{p}}$ the convexity assumption therefore yields $\mid x_{1}-$ $v \mid \leqslant \varepsilon D$. It follows that

$$
\left|2 x_{1}-x_{2}\right| \leqslant\left|x_{1}+v-x_{2}\right|+\left|x_{1}-v\right| \leqslant 2 \eta+\varepsilon D .
$$


Suppose that also $\left|x_{2}^{\prime}\right| \geqslant 2(D-\eta)$; then the same reasoning yields the same estimate on $\left|x_{2}^{\prime}-2 x_{1}\right|$ so that

$$
\left|x_{2}-x_{2}^{\prime}\right| \leqslant 4 \eta+2 D\left(\frac{2 \eta}{c D}\right)^{\frac{1}{p}}
$$

Now we can choose $\eta=K / D^{p-1}$ with $K$ small enough to ensure that the above inequality reads $\left|x_{2}-x_{2}^{\prime}\right|<$ 2 . This contradicts the hypothesis that $\varphi$ is distance non-decreasing, therefore as desired $\left|x_{2}\right|$ or $\left|x_{2}^{\prime}\right|$ must be smaller than $2(D-\eta)$.

\section{Acknowledgments}

I am grateful to Assaf Naor for interesting comments
[1] Jean Bourgain, The metrical interpretation of superreflexivity in Banach spaces, Israel J. Math. 56 (1986), no. 2, 222-230. MR 880292 (88e:46007)

[2] William B. Johnson and Gideon Schechtman, Diamond graphs and super-reflexivity, J. Topol. Anal. 1 (2009), no. 2, 177-189. MR 2541760 (2010k:52031)

[3] Jiří Matoušek, On embedding trees into uniformly convex Banach spaces, Israel J. Math. 114 (1999), 221-237. MR
1738681 (2001b:46028)

[4] Manor Mendel and Assaf Naor, Markov convexity and local rigidity of distorted metrics, J. Eur. Math. Soc. (JEMS) 15 (2013), no. 1, 287-337. MR 2998836 